International Journal of Embedded systems and Applications(IJESA) Vol.5, No.2, June 2015

\title{
DESIGN CHALLENGES IN WIRELESS FIRE SECURITY SENSOR NODES
}

\author{
S.R.Vijayalakshmi and S.Muruganand \\ Department of Electronics and Instrumentation, Bharathiar University,Coimbatore-46, \\ Tamilnadu, India.
}

\begin{abstract}
A design of simple hardware circuit with different kind of fire sensors enables every user to use this wireless fire security system. The challenges in designing the nodes with various types of fire sensors are discussed and the methods to overcome design problems are also analyzed. The circuit is interfaced with the different types of sensor to sense different fire sources such as gas leakage, smoke, and heat. The cost, circuit components, design requirements, power requirements of sensor node are minimized. The methods to improve the quality of system to detect fire are analyzed. The system is fully controlled by the PIC microcontroller. All the sensors and detectors are interconnected to PIC microcontroller by using various types of interface circuits. The PIC microcontroller will continuously monitor all the sensors and if it senses any security problem then the microcontroller will send the information to the PC central monitoring station wirelessly for a short distance of $300 \mathrm{~m}$ indoor $1500 \mathrm{~m}$ outdoor using zigbee technology. The gas sensor, light sensor, smoke detector sensor, IR sensor, temperature \& humidity sensor, fire sensor are interfaced with microcontroller to detect abnormal fire conditions in the environment in all possible ways.
\end{abstract}

\section{Keywords}

Security Systems - Smoke Sensor - wireless sensor nodes - wireless fire security sensor nodes.

\section{INTRODUCTION}

Fire security at industry or at home is the most important one. For everyone either in an individual house or an apartment or industry or any place, security is required and they must ensure that their industry/home is installed with the perfect and complete fire security monitoring system to protect their own life and property. This system can be used to provide fire security for all types of commercial, residential, domestic and industrial purposes using zigbee technique wirelessly. This paper discusses the aim to overcome the design challenges made by interfacing many sensor devices with PIC microcontroller to detect fire as it is most important in fire security. This proposed system is cheaper, consume less power and can be maintained easily by the user. For different type of fire sources such as smoke, electrical, gas leakage and heat can be detected by this single fire security system.

This device operates in two different modes. They are manual-mode and auto-mode. In case of manual mode, the user is inside the security area and for auto-mode the user is outside the wireless security area. The sensor node is initialized with auto-mode operation.

When the manual-mode is selected by the user the following events will be executed by the system. 
a) The entire sensors will be activated to sense.

b) Wireless interface module and all other units of PIC $\mu \mathrm{C}$ will be in sleep mode to save power.

c) The buzzer and actuators connected with the microcontroller will be activated for fire protection activities.

d) The reason for the insecurity will be displayed in the LCD connected to the microcontroller.

When the auto-mode is selected by the user the following events will be executed in sequence by the system.

a) Wireless interface module is activated for transmission and reception of RF signal.

b) The entire sensor will be activated to detect abnormal conditions in the environment.

c) The security area number along with its location which is pre-programmed, with the fire problem information will be sent to the PC central monitoring station wirelessly through XBEEPRO transceiver to the short range of $300 \mathrm{~m}$ indoor and $1500 \mathrm{~m}$ outdoor.

d) The security area number, its location along with cause of fire information are sent to the specified police station, fire station, security room and also to the user by the PC central monitoring station at the time of accident sensed by the sensors through the Internet using team viewer software.

This paper is organized as following chapters. The chapter 1 deals about the introduction. The chapter 2 discusses about the background study. The chapter 3 deals about the design challenges in interfacing various sensor to PIC microcontroller. The chapter 4 deals about experimental setup of the system. The chapter5 discusses about how the circuit results are analyzed. Last chapter deals about the conclusion.

\section{BACKGROUND STUDY}

The Sudipta Bhattacharjee [1] et al. analyzed about the wireless sensor network based fire detection, alarming, monitoring and prevention system for Bord-and-Pillar coal mines. The Zujue Chen [2] et al. discussed about the design of wireless sensor network node for carbon monoxide monitoring. The Hakilo Sabit [3] et al. discussed about the wireless sensor network based wildfire hazard prediction system modeling. The Andrey Somov [4] et al. analyzed about the deployment and evaluation of a wireless sensor network for methane leak detection.

As per the statistics, in India, 5.9\% [5] of total deaths during the year 2012 due to fires and related causes. Every year about 25000 persons die due to natural and unnatural causes of fire. Probably many of these deaths could have been prevented, if we had taken enough fire protection measures. According to Fire Risk Survey (FRS) 2013, in India, fire accounted for 8.45\% of the overall ranking of risks. It also stated that the 5th highest risk [6] is fire in industry during the year 2013.

Cetin Elmas [7] et al. analyzed about the data fusion framework with novel hybrid algorithm for multi-agent Decision Support System for forest fire. Yunus Emre Aslan [8] et al. discussed a framework for use of wireless sensor networks in forest fire detection and monitoring. Laura Díaz [9] dealt about the publishing sensor observations into geospatial information infrastructures for use case in fire danger assessment.

Most of the works are concentrated in the forest fire detection algorithms and architecture. This proposed work focuses on the different fire sources which causes fire accident in the 
International Journal of Embedded systems and Applications(IJESA) Vol.5, No.2, June 2015

city/industry/home. The different fire sources are sensed by the sensors such as photo electric, fire, smoke, light, Infrared, temperature and humidity.

Problem Analyze:From ancient days, fire represents threat to civil authorities. Fire threats are recognized as not only to the well-being of individuals, but also more importantly to the welfare and security of the community. In the days of wooden works, electrical items and high rise buildings, any fire could ravage an entire building. So, it is in the interest of all concerned to investigate fires, getting information about it and communicating it wirelessly to the short range. The causes of fire are different for different cases. Fire accident may cause due to smoke, gas leakage or electrical leakage.

The fire problem in India: Most of the State Fire Services do not have specialist fire fighting communication facilities and lack of fire fighting equipments. In metropolitan cities, high-rise buildings constitute major fire hazards. The buildings, therefore, can be death traps [6]. Urban fire services suffer deficiencies of $72.75 \%$ in fire stations, and $22.43 \%$ [6] in fire fighting and rescue vehicles. There is huge deficiency of fire fighting infrastructure in the towns having population more than 1lakh. There is an urgent need for creation of adequate number of well equipped fire stations in each State to extend fire cover to all areas within a reasonable time.

Problem statement: If the occupants of the place are alerted to fire quickly, the less risk of death, injury and less damage to the property as per the fire statistics. Furthermore, the property could be shifted to other places quickly, safely and immediately. But hard wired interconnection is having disadvantage of cost expensive, long time consuming and disruptive. A hard wired system is also very difficult and so expensive to reconfigure when circumstances change. If the methods use at the design of the wireless system and the components employ revolve around a compromise between effectiveness, compactness, low power requirements and cost.

Objectives: To develop the fire security system which is capable of checking and giving warning information to owner/police/fire/emergency medical during initial stages of fire wirelessly to the short range of $1500 \mathrm{~m}$ indoor $/ 300 \mathrm{~m}$ outdoor and thereby giving considerable amount of time for shifting to safe areas. The wireless home security fire sensor node which covers entire city (up to maximum of 65536 nodes) communicates the information to the PC central monitoring section at the distance of $1.5 \mathrm{Km} / 300 \mathrm{~m}$.

Aim: The main aim of this project work is to develop a wireless fire security control system for smoke, gas and fire detection. It uses wireless sensor networks (WSNs) concept to sense, process and communicate the fire. This system can be used to detect the exact fire location by assigning number and spreading direction. This also provides the fire prevention system to stop the spread of fire to save the natural resources by activating actuators. The proposed system is capable of detecting fire at its early stage and generating alarm and operating actuators in case of emergencies. This information is communicated to PC central monitoring station wirelessly at the distance of $1.5 \mathrm{Km}$. The same information could be viewed / transmitted to the fire service station, police station, owners and emergency medical care by the PC central monitoring station using the team viewer software. This project work is to design an efficient and cheap security system, which is accessible from any part of the world through the Internet. 


\section{Design Challenges In Interfacing Various Sensor To Pic Microcontroller:}

The challenges in designing the fire security sensor nodes are less cost, sensing different types of fire causes, interfacing different types of sensors, compactness, minimizing circuit components and less power requirements. This section discusses about the circuit which is interfaced with the different types of sensor to sense different fire sources. Hence, the methods to improve the quality of system by detecting fire are analyzed.

\subsection{Gas And Smoke Sensor:}

The MQ-2 sensor is used in this system to detect the gas leakage or smoke occurring in home/ industry. This sensor is used to detect gases like LPG/I-butane/propane/methane/ alcohol/hydrogen/ smoke. There are 7 different types of gas sensor are available based on detecting different gases. They are also available with different calibrating concentration. Here, this system is using an MQ-2 gas and smoke sensor which is capable to detect LPG and combustible gas/smoke. These 7 different kinds of gas sensors are shown in table 1.The type of sensor selected for the system is based on sensitivity of the sensor to detect gas based on the industry requirements.

Table 1: Types of Gas \& Smoke Sensor

\begin{tabular}{|l|l|}
\hline Sensor type & Detecting gas \\
\hline MQ-2 & LPG, I-butane, propane, methane, alcohol, Hydrogen, smoke \\
\hline MQ-3 & Alcohol, Benzene, CH4, Hexane, LPG, CO \\
\hline MQ-4 & Natural Gas/Methane \\
\hline MQ-5 & Coal gas, methane, LPG, H2,CH4, CO, Alcohol \\
\hline MQ-7 & CO \\
\hline MQ-8 & COAL Gas \\
\hline MQ-9 & LPG, CO, CH4 \\
\hline
\end{tabular}

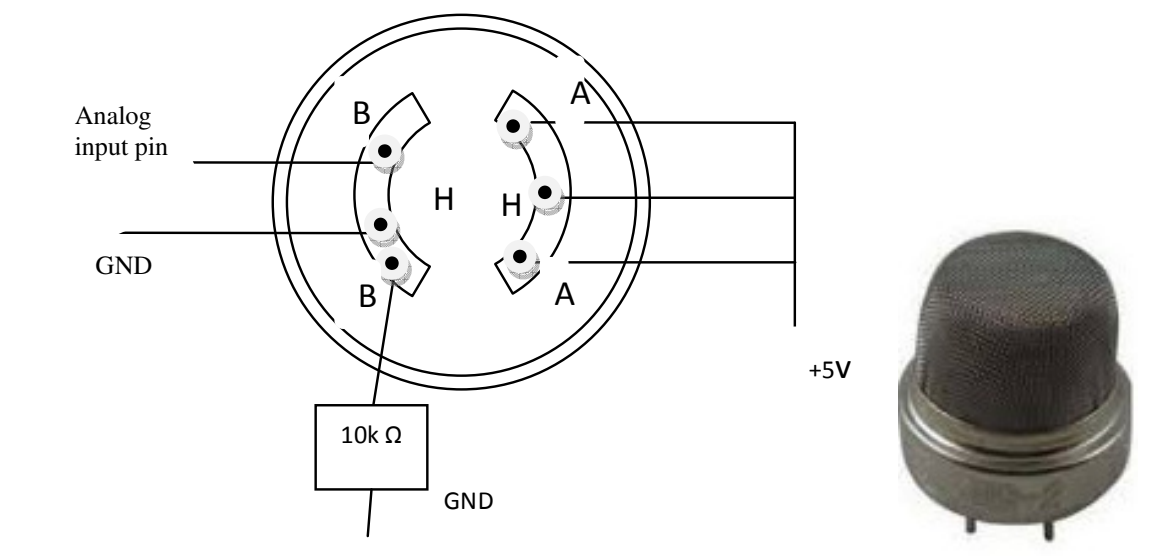

$+$

Figure: 1 Parts Description of Gas \& Smoke Sensor

The gas sensor consists of the heater, measuring electrode and tin dioxide sensitive layer. They are made by plastic and a stainless steel net. The heater is a work sensitive component which 
provides necessary work condition to detect gas. The figure 1 shows the parts description of gas and smoke sensor. The selection of gas sensor are made by the system to meet the low power, low cost, low interface circuits and type of gas to be detected.

The figure 2 shows that how the gas/smoke sensor MQ2 is interfaced with the PIC microcontroller. The gas/smoke sensor (MQ-2) has 6 pins totally. The two pins are used for providing heating current and 4 pins are used to catch the signal. The MQ-2 series IC is operated with 5 Volts power supply. Whenever the gas/smoke leakage is detected by the sensor, current passes through the heater coil to heat it. At particular temperature, the current passes through $1 \mathrm{~K} \Omega$ variable resistor. Due to this effect, voltage across Base-Emitter of NPN transistor 2N2222 is increased. At that time NPN transistor 2N2222 starts conducting. The resultant collector voltage of NPN transistor goes to zero. PIC Microcontroller input port pin is connected to the collector of NPN transistor 2N2222; hence microcontroller senses the gas leakage.

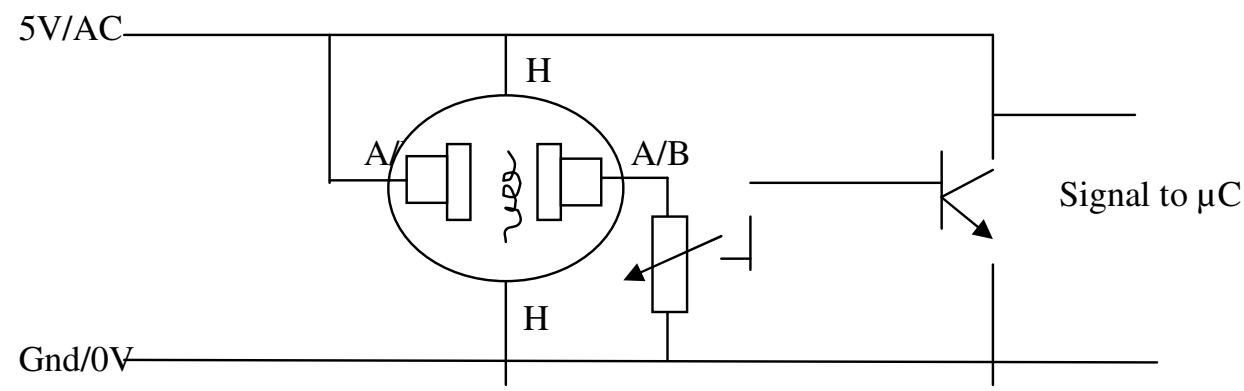

Figure: 2 Gas \& Smoke Sensor to Microcontroller Interface Circuit

\subsection{Humidity And Temperature Sensor Ic:}

The humidity and temperature measurement are done by IC SHT75. IC SHT75 is selected because of its features such as low power consumption, digital output, easy integration to circuits and excellent long term stability. The sensor can be easily interfaced to an $\mathrm{I}^{2} \mathrm{C}$ bus/serial bus of PIC microcontroller without disturbing other devices connected to the $\mathrm{I}^{2} \mathrm{C}$ bus of the PIC IC. The figure 3 shows the operating conditions of the sensor IC SHT75 for different values of temperature $\left(\mathrm{C}^{\circ}\right)$ versus relative humidity $(\%)$. The figure 4 shows the pin description of the sensor IC SHT75 and interfacing circuit with the microcontroller.

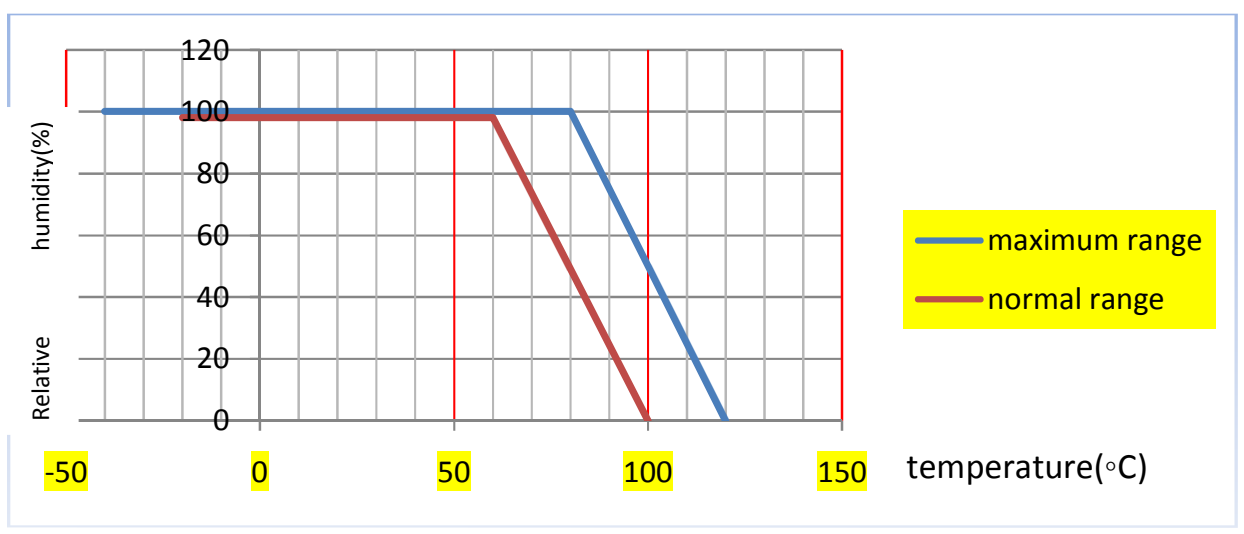



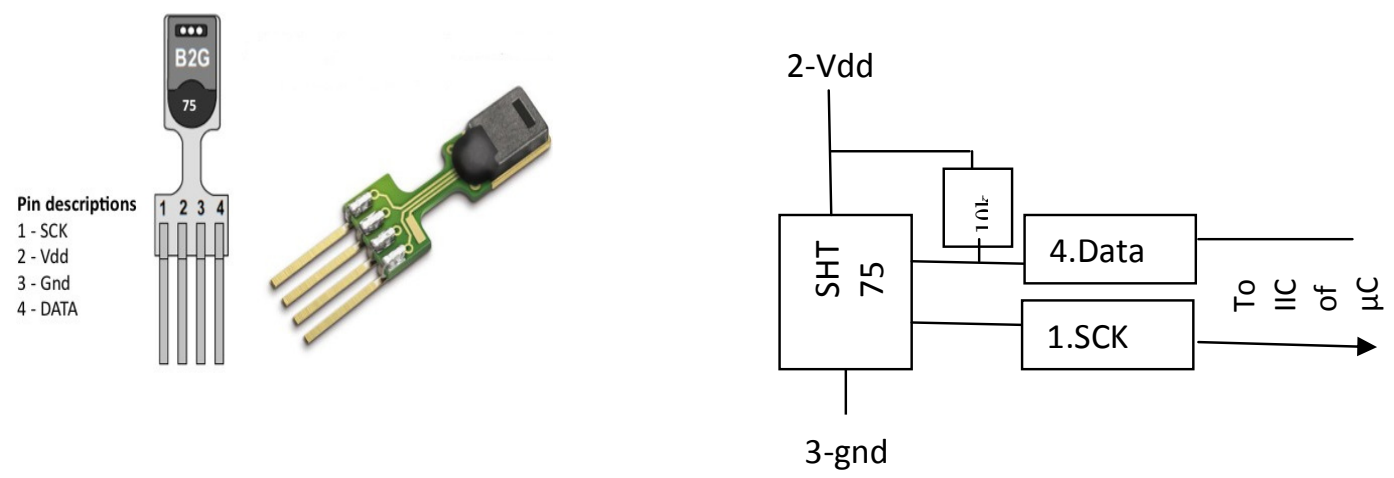

Figure: 4 SHT75 sensor pin descriptions and microcontroller interface circuit

\subsection{Ir Smoke Sensor:}

The smoke is detected by the optical smoke detector or photoelectric type device using a light source. The Infra-Red LED is a light source in IR smoke sensor. It also consists of a lens that shots a beam of light over a large area. If smoke is present in the environment, it enters into the optical chamber of sensor. The smoke particles scatter the light. So that sensor senses the smoke to indicate. In some case of IR smoke sensor, there are two optical detectors. They send the straight line of infrared beam from a sender to a receiver. The output from the IR smoke sensor is amplified to detect the smoke particles by the op-amp unit of PIC microcontroller. The figure 5 shows the working of IR sensor and interfacing circuit with the microcontroller. The smoke sensor is also selected based on low power, less interface components and type of sensing principle needed to detect smoke.

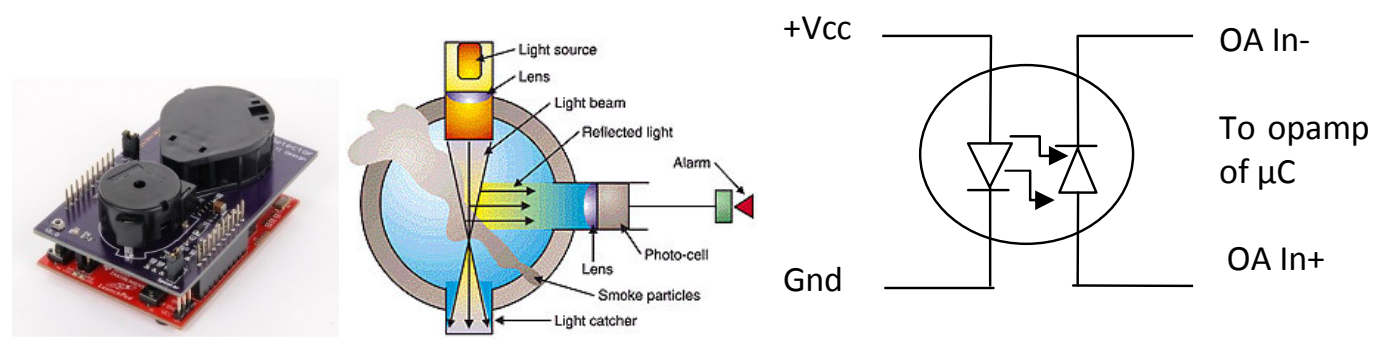

Figure 5: IR sensor working and microcontroller interface circuit

\subsection{Fire Sensor:}

The Fire sensor along with comparator is used to detect fire flames to the short range up to 1 meter. The $+5 \mathrm{~V}$ DC input voltage is needed to operate the unit. It sends the high voltage data to any one of port pin of microcontroller, when it detects the fire. Figure 6 indicates interface of fire sensor to PIC $\mu \mathrm{C}$. It sends low voltage data to the input port pin of PIC microcontroller, if there is no fire. This sensor is also used along with other sensor to ensure the fire accident situations. 


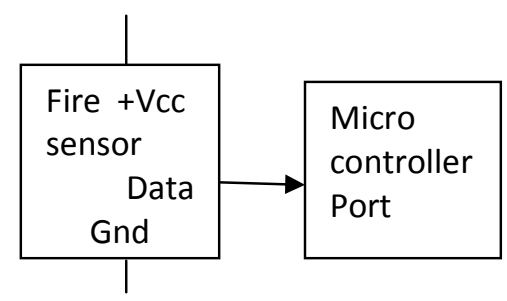

Figure 6: Fire sensor and microcontroller interface circuit

\subsection{Smoke Detector Sensor:}

The RE46C190 has features of low power, low voltage photoelectric type smoke detector IC to meet the design requirement of low power system. Hence this IC is selected to detect the smoke. It is interfaced with PIC microcontroller with fewer components. 3V power supply is applied between pin numbers 1 and 3. Pin 2 IRED provides a regulated and programmable pulsed current for the infrared emitter diode. Pin number 6 and 7 are connected to anode and cathode of photo diode respectively. The 8 and 9 output pins are connected to the microcontroller for alarm. Pin 11 of RE46C190 is used to charge the IR Led. Figure 7 indicates the smoke detector interface circuit with $\mu \mathrm{C}$.

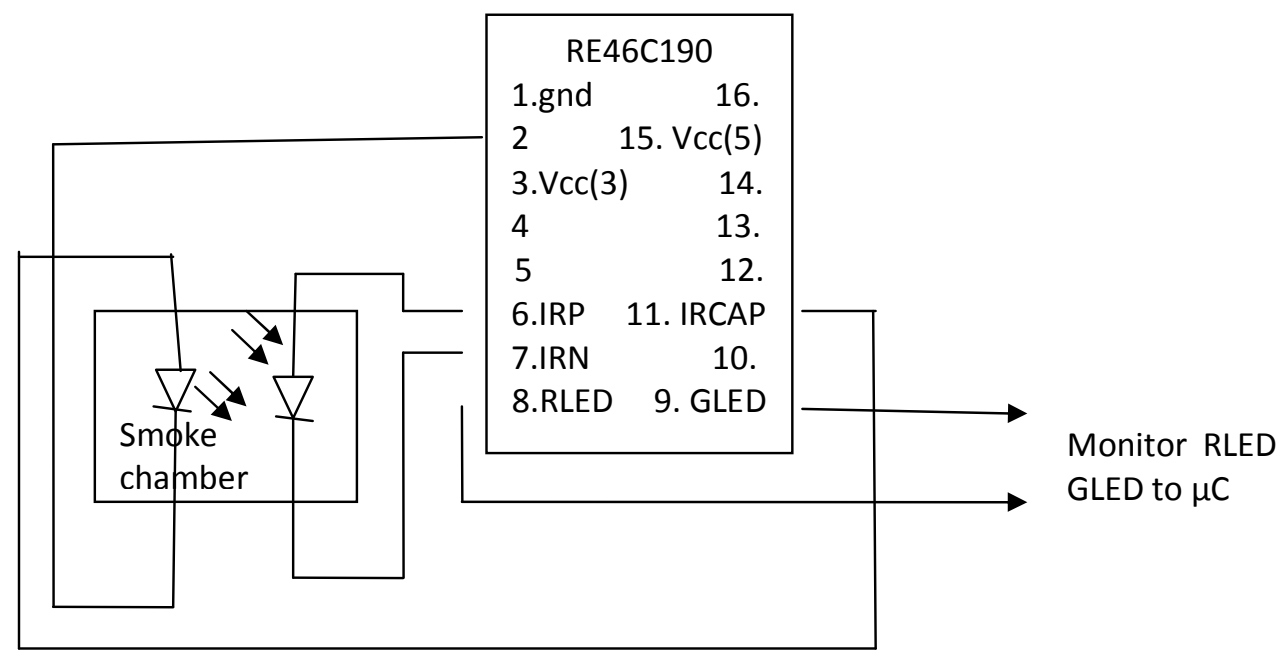

Figure 7. Smoke detector interface with microcontroller

\subsection{LIGHT SENSOR:}

The OPT101 photodiode with on-chip trans-impedance amplifier is selected to use as light sensor. The circuit is adjusted to give zero volts for no light and high voltage for a light. IC OPT101 is operated with 5V DC power supply. Pin-5 of light sensor IC $\left(\mathrm{V}_{\text {out }}\right)$ is interfaced with the input port pin of PIC microcontroller. This is used to detect whether the fire accident is happened 
during day time or night time. This IC is also used to compare the sunshine with fire to avoid mislead. The figure 8 shows the light sensor interfaced with PIC $\mu \mathrm{C}$.

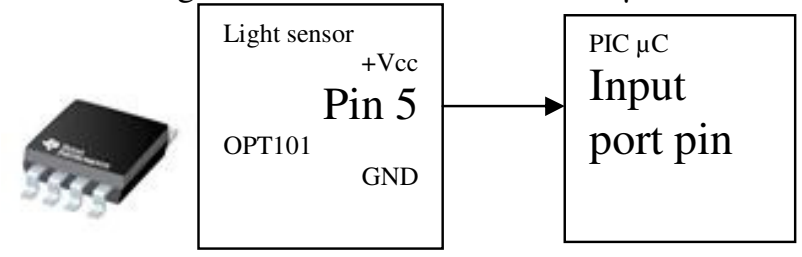

Figure 8. Light sensor OPT101 and interfacing with PIC $\mu \mathrm{C}$

\subsection{Tranceiver, Leds, Lcd, Switches And Buzzer Interface Circuit:}

The buzzer is used to make warning sound against gas,fire and smoke detection during manual mode selection. The output from the micro controller is $1.5 \mathrm{~V}$. The TPS61040IC high-frequency boost converter is used to boost $1.8-\mathrm{V}$ to $6-\mathrm{V}$ for LCD bias and to activate the buzzer in this system. UTXD0 and URXD0 of the PIC microcontroller are used to interface XBEE wireless module. These XBee modules are selected because of low-power, low-cost to meet our design requirements and application. These modules use the IEEE 802.15.4 networking protocol to meet all type of networking. Due to these features, these modules are very much suitable for designing fire security sensor nodes. The actuators are connected through relay circuit.

The LCD module is interfaced with PIC microcontroller for display of mode selection. The fire information, temperature humidity values are also displayed in the LCD. JTAG is interfaced with the microcontroller to program the PIC microcontroller. LEDs are connected with $\mu \mathrm{C}$ to indicate the conditions. Switches are connected with $\mu \mathrm{C}$ to select the modes. The figure 9 shows the XBEE pin description and microcontroller interface circuit.
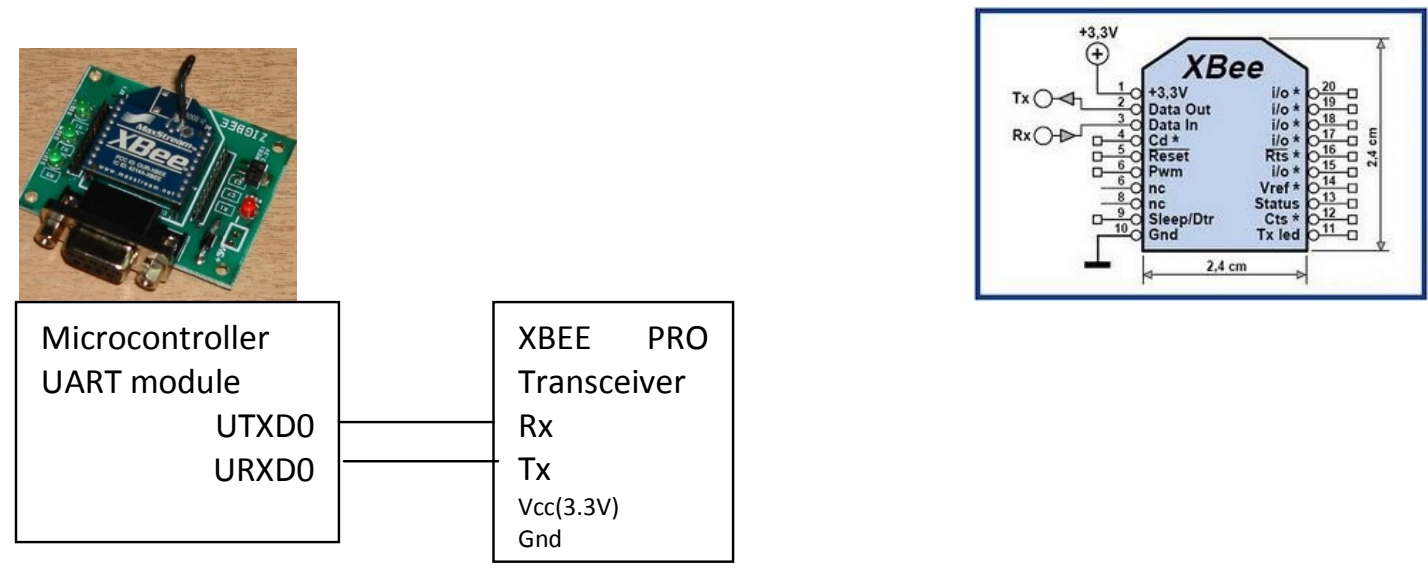

Figure 9: Xbee pin description and microcontroller interface circuit

The selection of PIC Microcontroller is done to meet low power, low cost and the all peripheral units to interface different types of sensors. MSP430 series is selected in this system. The PIC microcontroller will consist of timer module, peripheral ports, EPROM of 4M, RAM of $4 \mathrm{~K}$, opamp module, IIC/serial module, UART module to meet minimum requirements for the system. 


\section{Experimental Setup Of The System:}

The system is fully controlled by the PIC microcontroller and the microcontrollers will continuously monitor the sensors, detector and transceiver. The low power mode of PIC $\mu \mathrm{C}$ is chosen to reduce power consumption. The sensors are active only whenever it senses the fire or undesirable conditions. Immediately the sensed information is transmitted to the PC central monitoring station through the transceiver XBEE of sensor node to the distance of $1500 \mathrm{~m}$ outdoor.

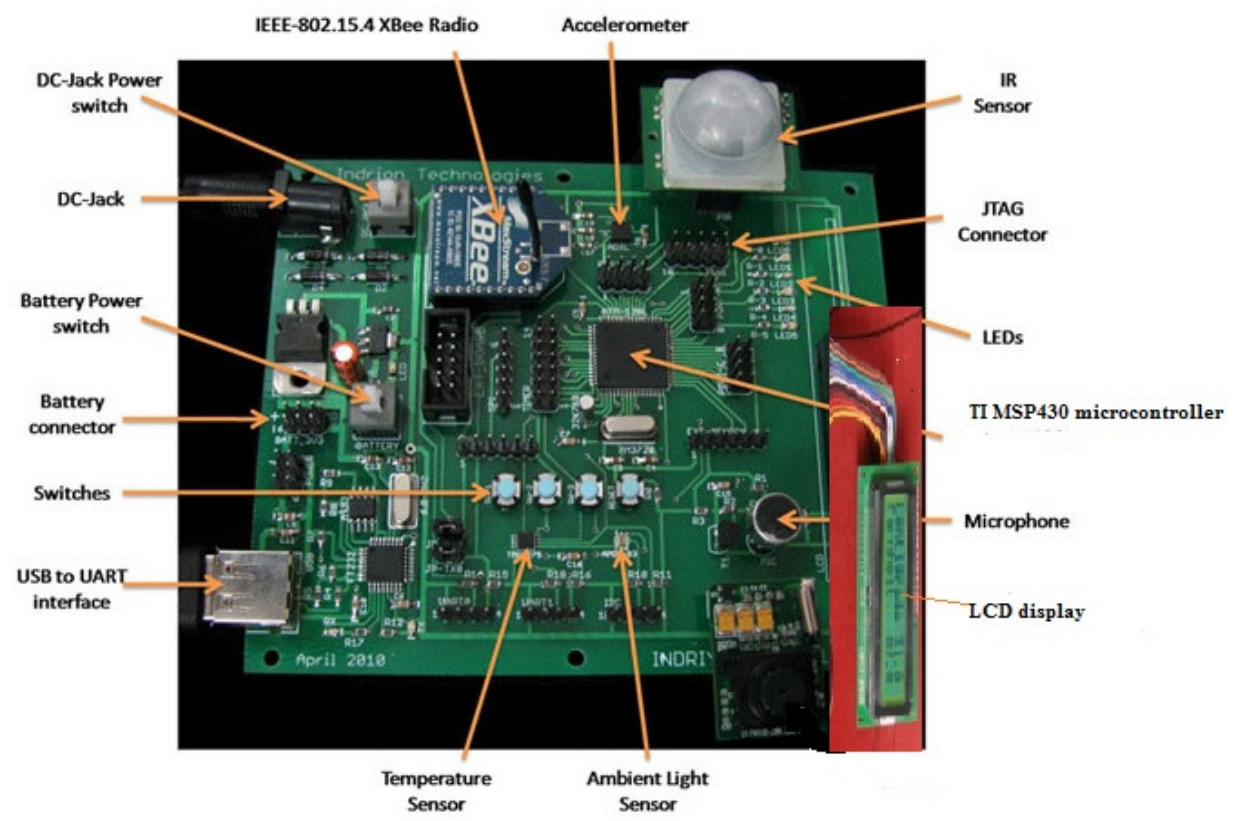

Figure 10. A simple method for interfacing sensors with microcontroller and transceiver

The figure 10 shows how different sensors are interfaced with microcontroller to sense the fire. These sensor nodes have 3 main functional units. They are (i) The sensor and their interface (ii) PIC microcontroller and (iii) The Communication Interface and actuators interface.

These wireless devices are offered to cover distance upto1.5km at line of sight $/ 300 \mathrm{~m}$ indoor. After detecting smoke, gas or a high temperature (potential fire), the security sensor node sets off the appropriate actions to prevent and inform. The security sensor node also transmits an RF signal to the PC central monitoring station located at the distance of $1500 \mathrm{~m}$ (outdoor) / $300 \mathrm{~m}$ (indoor). The PC monitoring station could able to monitor maximum of 65,536 sensor nodes that can cover the entire building/city.

Working Principle: The signal sensed by fire sensor, light sensor, gas sensor, smoke detector, temperature and humidity are sent to the microcontroller unit. In turn after processing data, PIC $\mu \mathrm{C}$ activates the actuators such as alarm circuit, water sprinklers relay, ventilation relay during 
abnormal condition and sends the information to the PC central monitoring station for display located at the distance of $1.5 \mathrm{Km}$ (outdoor) / $300 \mathrm{~m}$ (indoor).

The temperature \& humidity sensor unit is used as fire detection and control in this project and on activation, a signal is sent to the monitoring station via the microcontroller. The alarm circuit is also activated by comparing the temperatures. The light sensor is used to monitor day / night environment and send the information to the monitoring station. The light sensor is used to detect incident, whether it is night fire or day fire. The fire sensor also used to detect the fire accidents. The PC central monitoring unit is entirely software based and forms the control and display unit of the entire security system. All the detectors located entire building/city could be monitored through the display unit of PC central monitoring station. This information and database is available online and can be controlled from any internet-enabled computer. This information could be viewed by the civil authorities through team viewer software on real time. At the PC central monitoring station, a data base is maintained to store the locations of the security sensor nodes (maximum of 65536 security sensor nodes to cover entire buildings) and store/update the information collected by them.

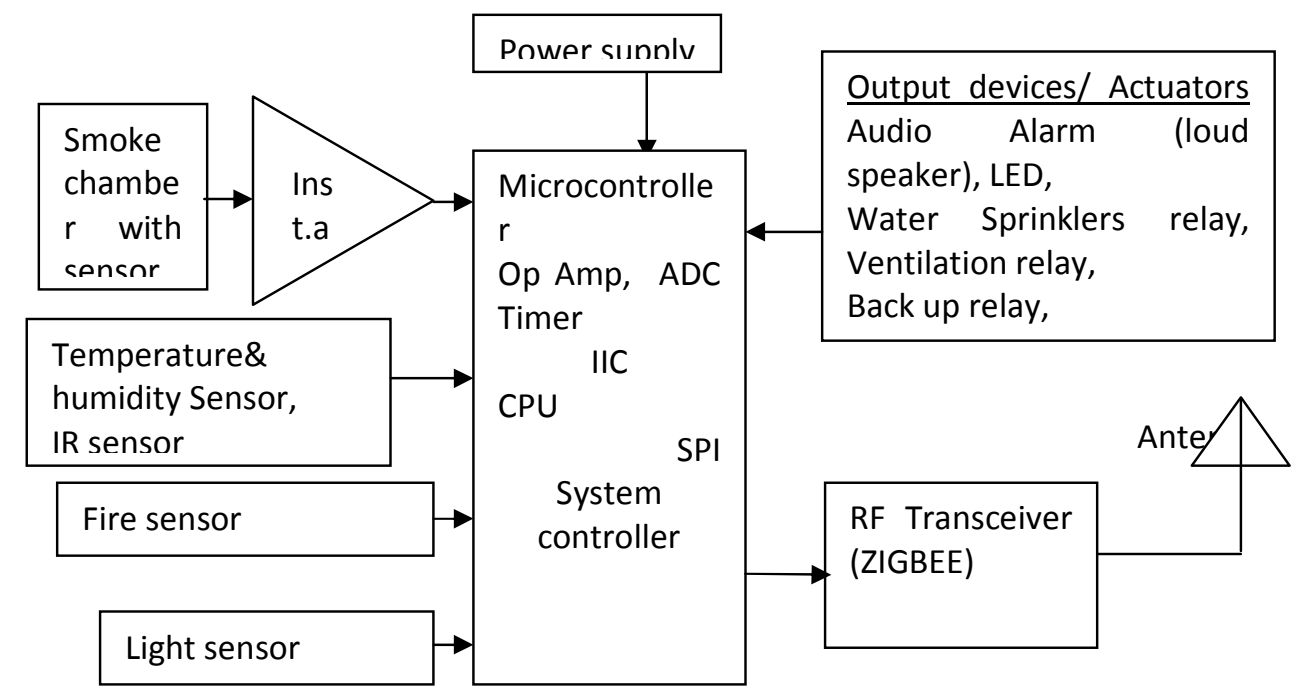

Figure 11. Block diagram of wireless fire security node design

The data from the entire sensor nodes are passed to the PC central monitoring station. At the sensor node the comparison algorithm is applied on the sensed temperature data of the observed area for fire detection. The data is received by the sensor node at 1 second intervals from the sensor. These data are compared with a specific threshold value using the algorithm. This process is carried out for every temperature data sensed by SHT75 IC. This is given in the equation 1. The timer module of PIC is used to generate $1 \mathrm{~s}$ interval.

$\operatorname{Alarm}(t)=\left\{\frac{1,|s(t)-s(t-1)| \geq \theta t}{0,|s(t)-s(t-1)| \leq \theta t}\right\} \quad$-----eq.(1)

In Equation (1) Alarm (t) represents the alarm state at $t$ time. $S(t)$ represents the temperature value at $\mathrm{t}$ time, and $\mathrm{S}(\mathrm{t}-1)$ represents the temperature value of 1 second ago at $(\mathrm{t}-1)$ time. If the 
difference between the temperatures values as per equation 1 exceeds the threshold value, the alarm and warning message will be sent.

The actuator unit will be activated for one of the following situations.

(i) Fire sensor senses fire.

(ii) The smoke detector detects smoke.

(iii) IR detector detects any abnormal conditions in the environment.

(iv) Gas sensor senses the gas.

(v) Temperature and humidity sensor senses the temperature and humidity values beyond the threshold.

Any one of these 5 conditions will indicate a fire at the observed area and system gets to the alarm state. There is no need to determine a threshold value for the smoke detector that it anyway gives alarm in case of smoke detection. The figure 11 gives the block diagram of wireless fire security sensor node.

The two major modules of sensor nodes are (i) the hardware module and (ii) the software module.

The hardware module of security sensor node will be designed to interface all the ICs required. The hardware module of monitoring section interface circuit will be designed to communicate with the sensor node using XBeePro and Max IC.

The Software Module should possess the following capabilities:

- Ability to handle data collection from microcontroller based security system

- Information from the sensors in the hardware sub modules were encoded and transmitted (to cover distance of $1.5 \mathrm{Km} / 300 \mathrm{~m}$ ) wirelessly by the home security sensor node to the receiving circuit interfaced with the computer.

- This information and database could be viewed by the civil authorities/ owner through team viewer software on real time.

- At the PC, a data base is maintained to store the locations of the home/city security sensor nodes (maximum of 65536 home security sensor nodes to cover entire building) and store/update the information collected by them.

- Suitable algorithm to detect fire accidents.

\section{Analyzing The Circuit Results:}

The sensors are selected such that they could be directly interfaced with the modules available in the microcontroller. So, the interfacing circuit components are very much reduced. Sensors are also selected to give direct digital output, small size and less power requirements. Modules are selected in low power mode and sleep mode whenever there is no emergency. During fire detection the information is transmitted to monitoring station without delay wirelessly to the distance of $1500 \mathrm{~m}$ outdoor/ $300 \mathrm{~m}$ indoor. 


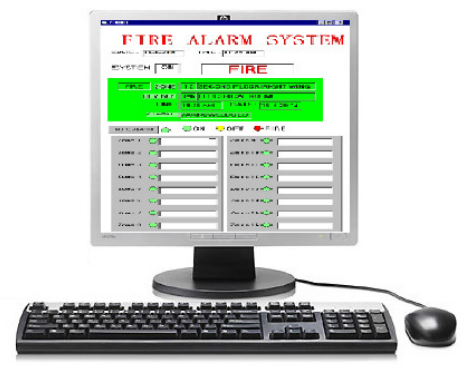

Figure 7 a

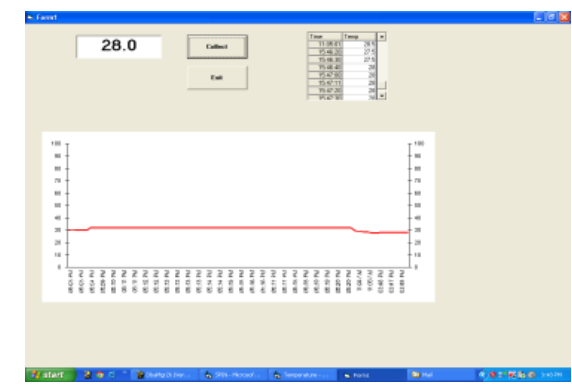

figure $7 \mathrm{~b}$

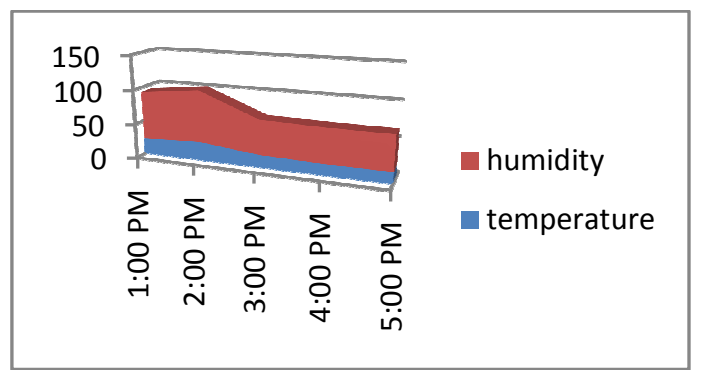

Figure $7 \mathrm{c}$

Figure. 7 Screen outputs a) node outputs at PC b) Temperature display

c) Relative humidity display

Due to simple, easy design requirements the cost of the overall system is reduced. The power requirements of the node are reduced by the careful design of the hardware and software. Owing to small size of the sensors, the entire node size is reduced much. Fire or not sensed by the sensor nodes located at a distance of $1.5 \mathrm{~km}$ is indicated at the PC central monitoring station is as shown in figure 7a. Green color indicates for no fire and red color indicates for fire. The temperature value and relative humidity value are displayed at the PC monitoring station of selected sensor node as shown in figure $7 \mathrm{~b}$ and $7 \mathrm{c}$.

\section{Advantage of wireless home/city security sensor node:}

Wireless home/city security alarm system is designed to detect the presence of fire/smoke/gas leakage by monitoring the environmental changes and to provide an early warning of fire that will notify people to evacuate and take immediate action to stop fire. This wireless system integrates with other alarm devices and to cover distances of $1.5 \mathrm{~km}$ (LOS outdoor)/300m (indoor).

\section{Less power consumption:}

In wireless sensor nodes power consumption is an important aspect. It should be reduced to meet long time monitoring requirement. With the help of battery fire sensor nodes need to be able to run for very long periods of time. This makes the selection of low power microcontroller for the application. The sensor is pulsed periodically and sampled by the microcontroller. Between sampling time and manual mode, the units are shut down. When the PIC microcontroller is in a standby mode consumes less power. The overall system is designed with low power consumption. 


\section{Conclusion:}

It is a real-time monitor and remote controlled system. This system is developed with simple hardware which simplifies the possibility of error free security system. This system can be easily implemented with maximum reliability and high security. Low cost is a special enhancement from the existing systems for fire security. This single node is sufficient to detect various types of fire causes.

In future many other gas sensors can be interfaced with the fire node. In future, the algorithms are also modified to find fire accident and to reduce power. In this fire security sensor node, the challenges of interfacing all different type of sensors are analyzed and achieved. The node consumes low power and battery operated. This system runs for long time. Different types of sensors such as fire sensor, IR sensor, smoke sensor, light sensor, temperature-humidity sensor and gas sensor are interfaced successfully with single PIC microcontroller. So that all different fire sources which causes fire accidents could be detected easily by the node.

\section{Acknowledgment:}

This work is supported by the University Grants Commission, Government of India under grant no. F.151/2014-15/PDFWM-2014-15-OB-TAM-24657.

\section{REFERENCES:}

[1] Sudipta Bhattacharjee et al., "Wireless sensor network-based fire detection, alarming, monitoring and prevention system for Bord-and-Pillar coal mines", The Journal of Systems and Software ,2012, vol. 85 , pp. 571- 581 .

[2] Zujue Chen et al. Design of wireless sensor network node for carbon monoxide Monitoring, Telecommunication Systems, 2013, vol.53, pp.47-53.

[3] Hakilo Sabit et al.,Wireless Sensor Network Based Wildfire Hazard Prediction System Modeling, Procedia Computer Science ,2011,vol.5,pp. 106-114.

[4] Andrey Somov et al., Deployment and evaluation of a wireless sensor network for methaneleak detection, Sensors and Actuators, 2013 ,Vol.202,pp.217- 225.

[5] www.fsai.in http://www.ind-safety.com

[6] http://ndrfandcd.gov.in/Fire.aspx

[7] Cetin Elmas et al., A data fusion framework with novel hybrid algorithm for multi-agent Decision Support System for Forest Fire, Expert Systems with Applications, vol.38,2011,pp.9225-9236.

[8] Yunus Emre Aslan et al., A framework for use of wireless sensor networks in forest fire detection and monitoring, Computers Environment and Urban Systems, Vol.36, 2012, pp. 614-625.

[9] Laura Díaz et al., Publishing sensor observations into Geospatial Information Infrastructures: A use case in fire danger assessment, Environmental Modelling \& Software, Vol.48, 2013, pp. 65-80.

\section{Authors:}

S.R.Vijayalakshmi is a Post Doctoral research Fellow in Department of Electronics and Instrumentation in Bharathiar University. She received her B.Sc. M.Sc. M.Phil. and Ph.D in Electronics from the Bharathiar University and also received M.Sc. in Computer Science from Bharathiar University and M.Phil. in Computer Science from Avinashilingam University. She has experience in the teaching field and also in 
International Journal of Embedded systems and Applications(IJESA) Vol.5, No.2, June 2015

research. Her research interests include digital image processing, embedded systems, real time systems, wireless sensor networks and Microprocessors. She completed one DST-WOS-A project funded by Government of India.

S.Muruganand is an Assistant Professor in Department of Electronics and Instrumentation in Bharathiar University. He received his M.Sc. Physics from Madras University, M.Ed. from Annamalai University and Ph.D from Bharathiar University. He has 25 years of experience in the teaching and research field. His research interests include digital image processing, embedded systems, nano science, power electronics, wireless sensor networks, thin films, biomedical and Microprocessors. He completed one UGC- Minor project funded by Government of India. He is author of many papers in the referred journals. 